\title{
Preparation and Characterization of Zeolite Membrane for Bioethanol Purification
}

\author{
Aprilina Purbasari' ${ }^{1}$ Titik Istirokhatun ${ }^{2}$, Ariestya Meta Devi' ${ }^{1}$, \\ Lulluil Mahsunnah¹, Heru Susanto*1
}
${ }^{1}$ Department of Chemical Engineering, Faculty of Engineering, Diponegoro University, Jl. Prof. Soedarto, Kampus Undip Tembalang, Semarang 50275, Indonesia

${ }^{2}$ Department of Environmental Engineering, Faculty of Engineering, Diponegoro University, Jl. Prof. Soedarto, Kampus Undip Tembalang, Semarang 50275, Indonesia

Received: 23rd October 2012; Revised: 15th February 2013; Accepted: 16th February 2013

\begin{abstract}
The use of bioethanol as an alternative fuel with a purity of more than $99.5 \%$ wt has prompted research on bioethanol purification. One of the promising methods used for bioethanol purification is pervaporation. This research is aimed to prepare and characterize zeolite membranes for pervaporation. The membrane preparation consisted of two stages, namely support layer preparation and zeolite deposition on the support. In support preparation, a-alumina and kaolin with specific composition (50:30; 40:40; 50:30) was mixed with additives and water. After pugging and aging process, the mixture was extruded into a tubular shape. The tube was then calcined at temperature of $1250^{\circ} \mathrm{C}$ for 3 hours. After that, zeolite $4 \mathrm{~A}$ was deposited on the tubes using clear solution made of $10 \%$ wt zeolite and $90 \%$ wt water and heated at temperature of $80{ }^{\circ} \mathrm{C}$ for 3 hours. Furthermore, the resulting zeolite membrane was washed with deionized water for 5 minutes and dried in oven at temperature of $100{ }^{\circ} \mathrm{C}$ for 24 hours. Characterization of zeolite membranes included mechanical strength test, XRD, and SEM. In the mechanical strength test, the membrane sample with a-alumina:kaolin $=50: 30$ (membrane A) had the highest mechanical strength of $46.65 \mathrm{~N} / \mathrm{mm}^{2}$. Result of the XRD analysis for the membrane A indicated that mullite and corundum phases were formed, where mullite phase was more dominant. Meanwhile the result of SEM analysis showed that zeolite crystals have been formed and covered the pores support, but the deposition of zeolite has not been optimal yet. The ethanol product concentration and permeate flux were influenced by the feed temperature, feed concentration and permeate pressure. The performance examination for bioethanol purification showed that the membrane could increase the purity of bioethanol with maximum purity was 98.5\% wt. C) 2013 BCREC UNDIP. All rights reserved. (Selected Paper from International Conference on Chemical and Material Engineering (ICCME) 2012)
\end{abstract}

Keywords: Alumina; Bioethanol; Inorganic membrane; Kaoline; Zeolite

How to Cite: Purbasari, A., Istirokhatun, T., Devi, A.M., Mahsunnah, L. , Susanto, H. (2013). Preparation and Characterization of Zeolite Membrane for Bioethanol Purification. Bulletin of Chemical Reaction Engineering \& Catalysis, 8 (1): 47-53. (doi:10.9767/bcrec.8.1.4062.47-53)

Permalink/DOI: http://dx.doi.org/10.9767/bcrec.8.1.4062.47-53

* Corresponding Author.

E-mail: heru.susanto@undip.ac.id (H. Susanto)

Tel. +62-24-7460058; Fax.: +62-24-76480675 


\section{Introduction}

Bioethanol can be used either as an additive or as a pure fuel (fuel grade). Moreover, bioethanol fueled vehicles produce lower carbon monoxide and carbon dioxide emissions, and the same or lower levels of hydrocarbon and oxides of nitrogen emissions. However, the purity of bioethanol is currently the main issue of this realization. Most of the Indonesian bioethanol industries are only able to produce bioethanol with purity of less than $95 \%$. To be used as a pure fuel, bioethanol should have a purity greater than $99.5 \%$ (Indonesian National Standard, SNI).

A problem of bioethanol purification is the formation of bioethanol-water azeotropic mixture at a concentration of $\sim 95 \%$. Distillation, a separation technology based on boiling point difference, cannot be used anymore to enhance bioethanol concentration of $>95 \%$. Several methods have been proposed for the dehydration of bioethanol including molecular sieve adsorption system [1,2] and entrainer distillation [3-5]. Both of these technologies in principle can increase the bioethanol purity, but the complexity and high operating costs hinder the industrial scale applications. More recently, pervaporation technology using a hydrophilic polymer membrane has been offered as the dehydration of organic solvents. Pervaporation is a separation process using membrane, in which a feed is contacted and passed through a membrane that preferentially permeates on or more of the feed components. The driving force of this process is the vapor pressure difference between feed and permeate sides. Separation process occurs due to differing rates of diffusion through a membrane and an evaporative phase change comparable to a simple flash step. A vacuum is usually applied to the permeate side in order to increase both separation factor and flux. Reader, who interested in mass transport mechanism in pervaporation is directed to Baker [6].

The hybrid process combining distillation and pervaporation technologies resulted in better performance and more competitive compared to conventional processes. However, swelling, a process of wetting and swelling of the membrane pores by solvent (bioethanol), decreases the performance of the process. The swelling process causes the loss of selectivity causing a decrease in concentration of bioethanol product. To solve this swelling problem, inorganic membranes have been proposed to replace the polymeric membrane [7-9].

Inorganic membranes, also referred to as ceramic membranes, are made of silica, alumina or zeolite possessing highly resistant to solvents, high temperature stability, and free from swelling. Therefore, these membranes can be used in appli- cations with a wide range and at the same time these membranes have high selectivity and permeability.

Zeolite membrane has been proposed for pervaporation process due to its unique characteristics such as pore size; the nature of adsorption; mechanical, chemical and biological stabilities. Zeolite membranes have so far shown good separation performance, but the permeate results are still low for practical applications. One of the challenges for preparing zeolite membranes is to make zeolite membranes with high both permeability and selectivity. In order to obtain a better separation performance, preferably zeolite membranes are made of pure zeolite crystals in small size and uniform particle. Several methods are reported for zeolite membranes synthesis $[6,8,9]$. The structural stability of zeolite membrane and consequently its performance are affected by its support. The most commonly supports used are stainless steel and alumina in tubular or plated form. Alumina supports typically have pore diameter within the range $5 \mathrm{~nm}$ (gamma- $\mathrm{Al}_{2} \mathrm{O}_{3}$ ) to $200 \mathrm{~nm}$ (Alpha$\mathrm{Al}_{2} \mathrm{O}_{3}$ ), while stainless steel supports within the range 0.5 to $4.0 \mu \mathrm{m}$. Two critical stages occur during the formation of zeolite membranes support, namely the nucleation on the support followed by crystal growth to form a continuous zeolite layer and cover support. There are several methods of zeolite membranes synthesis, i.e. hydrothermal synthesis method, secondary growth method, continuous flow synthesis method, and microwave synthesis method.

This paper presents the preparation of zeolite membrane for bioethanol purification using local (Indonesia) raw material. To the best of our knowledge, there is no previous study on the preparation of pervaporation membrane using Indonesian's materials. Difference in raw material used (such as the origin of the material) causes difference in formula or composition that should be used for membrane preparation. The purposes of this research are to determine the optimal composition of the support for zeolite membranes preparation, to study preparation of zeolite membrane, and to characterize the resulting zeolite membranes.

\section{Materials and Method}

\subsection{Materials and Instrumentations}

In this experiment, polyethylene glycol (PEG) was purchased from Sigma Aldrich. Magnesium sulfate $\left(\mathrm{MgSO}_{4}\right)$ and $\mathrm{a}$-alumina were purchased from Merck. Kaolin and carboxymethyl cellulose were local products, which were purchased from CV. Indrasari, Semarang, Indonesia. 


\subsection{Methods}

\subsubsection{Porous support preparation}

Preparation of zeolite membrane consisted of two stages, namely support preparation and zeolite deposition on the prepared support. In support preparation, a-alumina and kaolin with a certain ratio, i.e. a-alumina : kaolin $=50 \mathrm{~g}: 30 \mathrm{~g}$ (labelled as sample A), a-alumina : kaolin $=40 \mathrm{~g}: 40 \mathrm{~g}$ (labelled as sample B) or a alumina:kaolin = $30 \mathrm{~g}$ : $50 \mathrm{~g}$ (labelled as sample $\mathrm{C}$ ), was mixed with additives ( $2 \mathrm{~g}$ carboxymethyl cellulose, $0.8 \mathrm{ml}$ polyethylene glycol, $2 \mathrm{~g}$ sodium citrate, and $2 \mathrm{~g} \mathrm{MgSO}_{4}$ ) until homogeneous and was left for 15 minutes. Then, water (with the quantity was $45 \%$ of the total weight of solid) was added to the mixture drop by drop. To make the solid mixture in a paste form, pugging was applied to the mixture for 30 minutes followed by aging for 30 minutes. The paste was extruded into tube shape using an extruder. The resulting tubular support was dried at room temperature for 3 days and then calcined at temperature of $1250^{\circ} \mathrm{C}$ for 3 hours.

\subsubsection{Deposition of zeolite on porous support layer}

Zeolite deposition on porous support layer followed the method developed by Aguado et al. [10]. Initially a clear solution was prepared by dissolving $10 \%$ wt. zeolite and $90 \%$ wt. water followed by heating and stirring until the solution was saturated. Clear solution was heated to a constant temperature of $80{ }^{\circ} \mathrm{C}$ and then tubular support was immersed into the clear solution with stirring for 3 hours. Thereafter, the resulting membrane was dried at room temperature for 30 minutes and washed using deionized water for 5 minutes. Further, the membrane was dried at 100 ${ }^{\circ} \mathrm{C}$ for 24 hours. All experiments were performed in triplicate. The membrane was characterized by mechanical strength test, XRD (X-Ray Diffraction), and SEM (Scanning Electron Microscopy). The resulting membrane was then examined for bioethanol purification.

\subsubsection{Pervaporation experiment}

Pervaporation experiment was performed by using a self-homemade laboratory scale for pervaporation test (Figure 1). In general, the apparatus consisted of a feed tank, a feed pump, membrane cell, a vacuum pump and heating bath with circulation pump. Feed solution with certain concentration was heated until the desired temperatur and pumped to the membrane cell. Vacuum condition was applied from permeate side of the membrane cell. The resulting permeate was cooled and

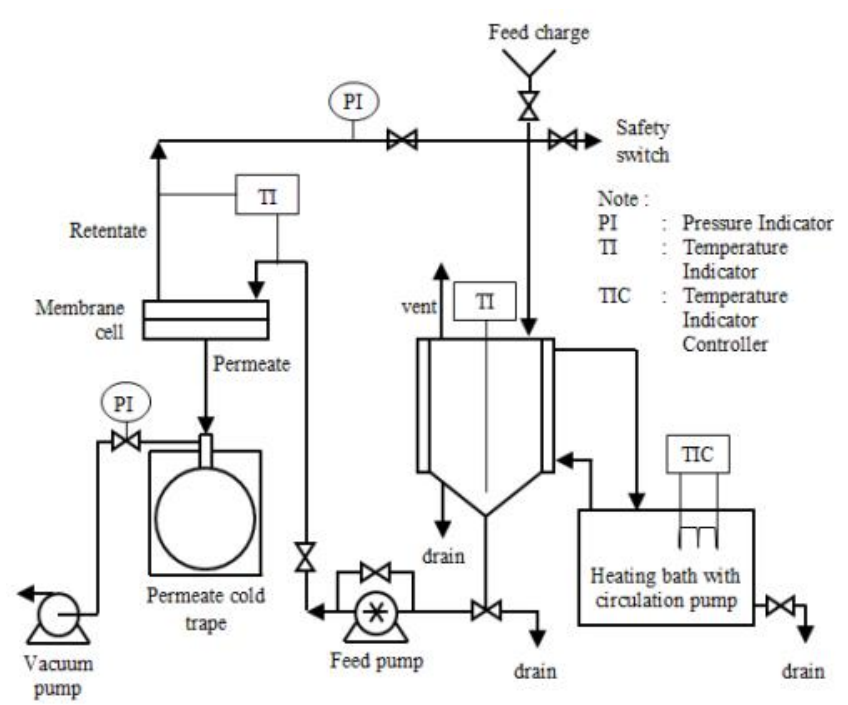

Figure 1. Schematic diagram of the pervaporation apparatus

collected in a liquid trap. The retentad was circulated back to the feed solution tank.

\section{Results and Discussion}

\subsection{Mechanical Strength}

The mechanical strength characterization results are presented in Table 1 . It is seen that sample A has the highest mechanical strength, i.e. 46.65 N/mm², while for both samples B and C are $18.50 \mathrm{~N} / \mathrm{mm}^{2}$ and $12.40 \mathrm{~N} / \mathrm{mm}^{2}$, respectively. The support layer was prepared via high temperature firing. During this step, many processes could occur such as: evaporation of crystalline water at temperatures of $450-700{ }^{\circ} \mathrm{C}$, dehydration of aluminum hydrates at temperatures of $320-560{ }^{\circ} \mathrm{C}$, oxidation of organic matter, which generally occurs at $200-700{ }^{\circ} \mathrm{C}$, and oxidation of coarse carbon particles can occurs at $\sim 1000{ }^{\circ} \mathrm{C}$. Besides those processes, particles in ceramics would join together into an aggregate that has strength at sintering process [11]. It is clearly seen that the increase in alumina content increases the mechanical strength of the support layer. Sample A, which contained the highest a-alumina shows the highest mechanical strength; consequently sample A was used for further zeolite membrane preparation.

Table 1. Mechanical strength of support layer

\begin{tabular}{cc}
\hline Sample & Mechanical Strength $\left(\mathrm{N} / \mathrm{mm}^{2}\right)$ \\
\hline A & 46.65 \\
B & 18.50 \\
C & 12.40 \\
\hline
\end{tabular}




\subsection{XRD Analysis}

\subsubsection{Identification of Formed Phase}

XRD analysis was conducted by means of Hanawalt method using the Data Base of JCPDS (Joint Committee of Powder Diffraction Standard). The result shows that corundum and mullite phases were formed in sample A with mullite was the dominant phase (Figure 2). In this composition, the formed corundum phase $\left(\mathrm{Al}_{2} \mathrm{O}_{3}\right.$, Aluminum Oxide) appears at the top with angle $2 \theta: 35.255 ; 37.873$; $43.451 ; 53.97 ; 57.598 ; 64.675 ; 66.531 ; 68.227$; 76.902. Meanwhile, the formed mullite phase appears at the top with angle $2 \theta: 12.68 ; 25.679$; $33.314 ; 35.255 ; 40.992 ; 61.424$.

\subsubsection{Crystal Size}

Crystal size was calculated using the following Scherrer equation (Equation 1):

$$
L_{\text {ave }}=\frac{k \lambda}{B_{o} \cos \theta}
$$

where $L_{a v e}$ is the crystal size, $k$ is a constant, $B_{0}$ is the width at half-maximum (FWHM) of peak and $\theta$ is the diffraction angle. Determination of crystal size was performed using full width half maximum (FWHM). Crystal size determination in sample A obtained from the XRD result is presented in Table 2. It can be seen in Table 2 that the size of formed crystals on sample A was within the range 3.398-

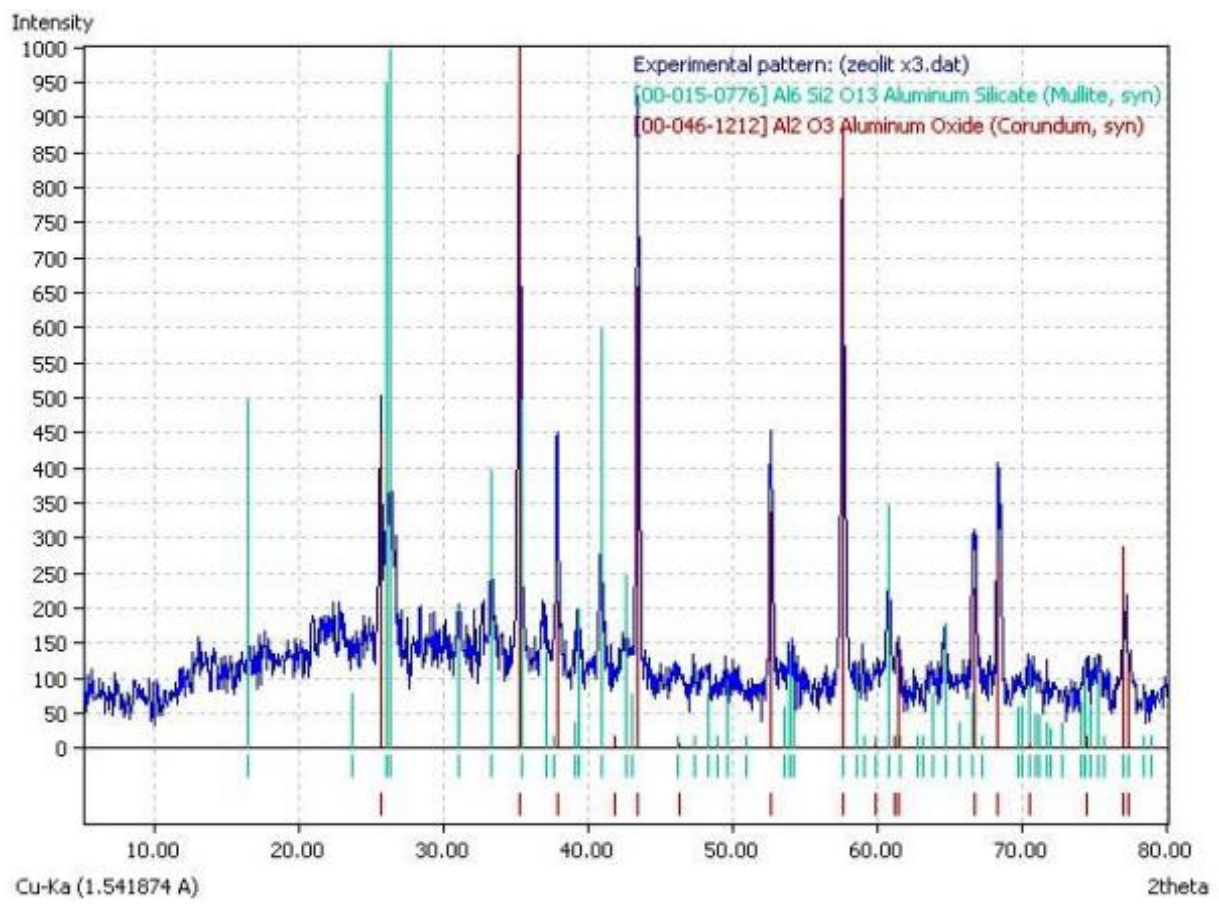

Figure 2. XRD analysis of sample A

Table 2. Crystal sizes in sample A

\begin{tabular}{cccccc}
\hline & \multicolumn{2}{c}{$\begin{array}{c}\text { Corundum Phase } \\
\left(\mathrm{Al}_{2} \mathrm{O}_{3}\right)\end{array}$} & \multicolumn{3}{c}{$\begin{array}{c}\text { Mullite Phase } \\
\left(\mathrm{Al}_{6} \mathrm{Si}_{2} \mathrm{O}_{13}\right)\end{array}$} \\
\hline $2 \theta$ & FWHM & Crystal size $(\mathrm{nm})$ & $2 \theta$ & FWHM & Crystal size (nm) \\
\hline 35.255 & 0.5 & 3.398 & 12.68 & 0.45 & 3.16 \\
37.873 & 0.45 & 3.906 & 25.679 & 0.45 & 3.42 \\
43.451 & 0.5 & 3.823 & 33.314 & 0.6 & 2.76 \\
53.973 & 0.4 & 5.897 & 35.255 & 0.5 & 3.39 \\
57.598 & 0.5 & 5.179 & 40.992 & 0.5 & 3.67 \\
$64.67 \mathrm{~s}$ & 0.4 & 8.109 & 61.424 & 0.4 & \\
66.531 & 0.5 & 6.96 & & & \\
68.227 & 0.45 & 8.31 & & & \\
76.902 & 0.5 & 12.246 & & &
\end{tabular}


12.246 $\mathrm{nm}$ for corundum phase and 3.16-7.25 nm for mullite phase.

\subsection{SEM Imaging}

\subsubsection{Comparison of support surface and zeo- lite membrane surface}

The surfaces of support layer and zeolite membrane were visualized using SEM. The results are presented in Figures 3 and 4.

From Figure 3, it can be observed that the support surface is covered by alumina bond derived from a-alumina and kaolin uneven. The disorder bond caused pores formation on the support surface. Figure 4 shows a smoother surface than Figure 3 indicating that the support surface layer has been coated by zeolite $4 \mathrm{~A}$. It seems that zeolite deposition could occupy the surface depression in

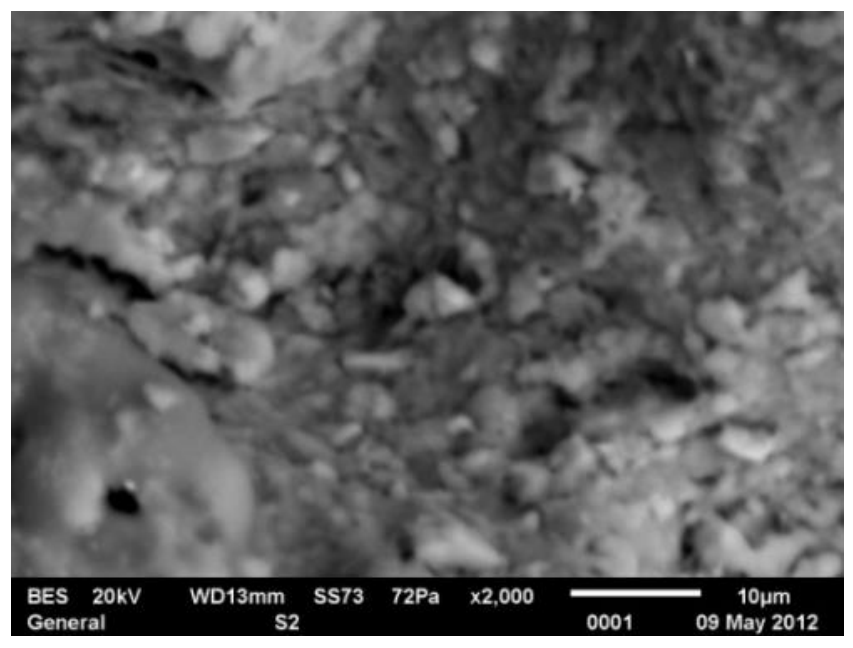

Figure 3. SEM image of the top surface of support layer

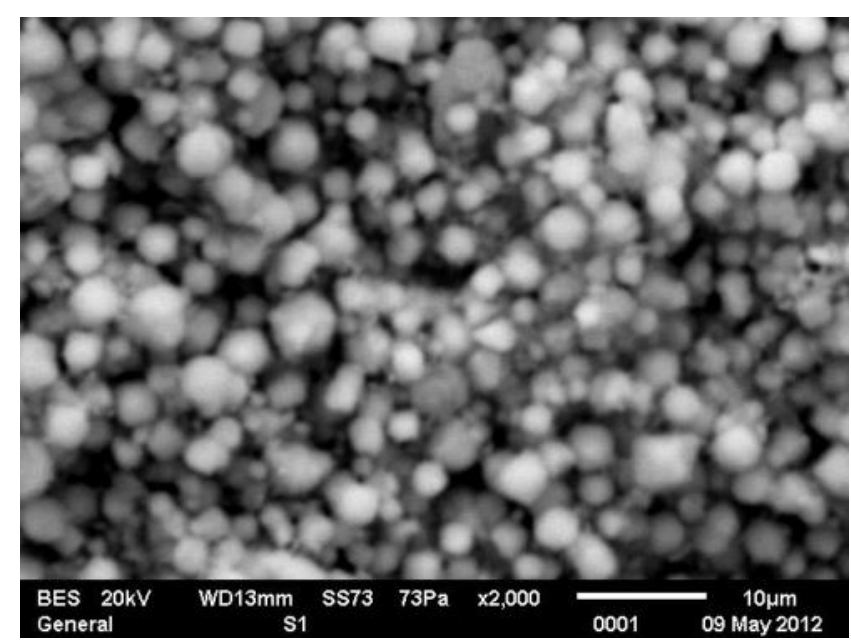

Figure 4. SEM image of the top surface of zeolite membrane greater amount causing the surface smoother

Comparing the surface morphology of the resulting zeolite membrane with the zeolite membrane in previous publication (Figure 5) shows that the surface morphology of the zeolite membranes by Wee et al. [12] formed zeolite crystals, which covers membrane support homogenously. In this experiment, the formation of zeolite crystals has not reached optimal condition yet as indicated by zeolite crystals spread unevenly on the entire surface of the membrane. Thus, some cavities can still be observed.

\subsection{Test results for bioethanol purification}

In order to know the membrane performance, the resulting membrane A was examined for bioethanol purification using pervaporation test unit (Figure 1). The experimental results are presented Figure 6, 7, 8. It is seen from Figure 6 that the increase in feed temperature decreases ethanol product concentration. By contrast the permeate flux was increased by increasing feed temperature. The increase in feed temperature would increase the feed vapor pressure resulting more vapor penetration to the permeate side. In addition, the increase in temperature can cause swelling process, which will enlarge the free volume of membrane. Consequently, the selectivity of the membrane will decrease and hence the ethanol product concentration will decrease.

As the ethanol concentration in the feed was increased, the concentration of ethanol product would also increase, whereas the permeate flux would decrease (Figure 7). The increase in ethanol concentration means the amount of water that can be penetrated to the permeated side decreases. In other words, the increase in concentration decreas-

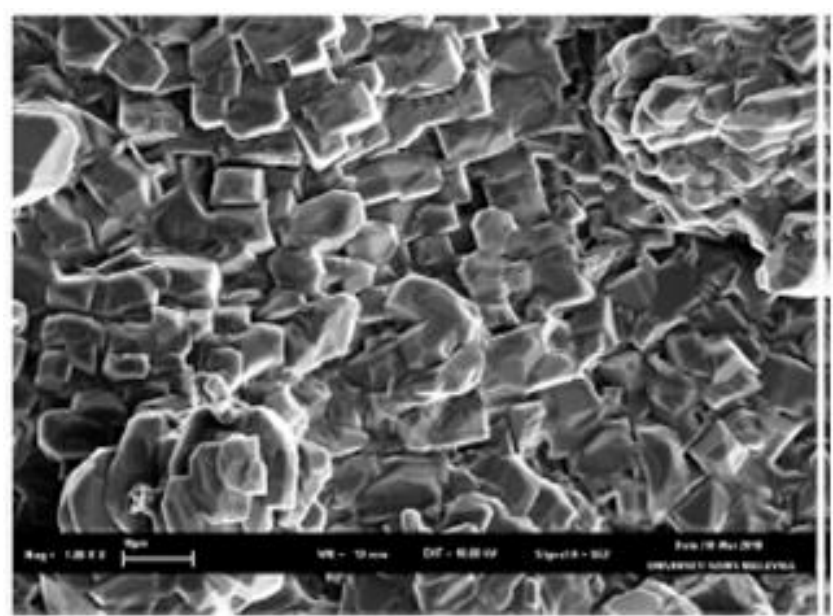

Figure 5. Top view of zeolite membrane from previous study [11] 
es the feed vapor pressure leading to a decrease in permeation rate.

The increase in permeate pressure decreases both flux and ethanol product concentration. This phenomenon can be explained from the existing driving force. Difference in vapor pressure is the driving force for the pervaporation membrane process. Increasing permeate pressure would increase vapor pressure in permeate site resulting a decrease in vapor pressure difference between feed and permeate sides.

Overall the results (Figures 6 - 8) show that the resulting membrane has followed a process mechanism of pervaporation process. The concentration

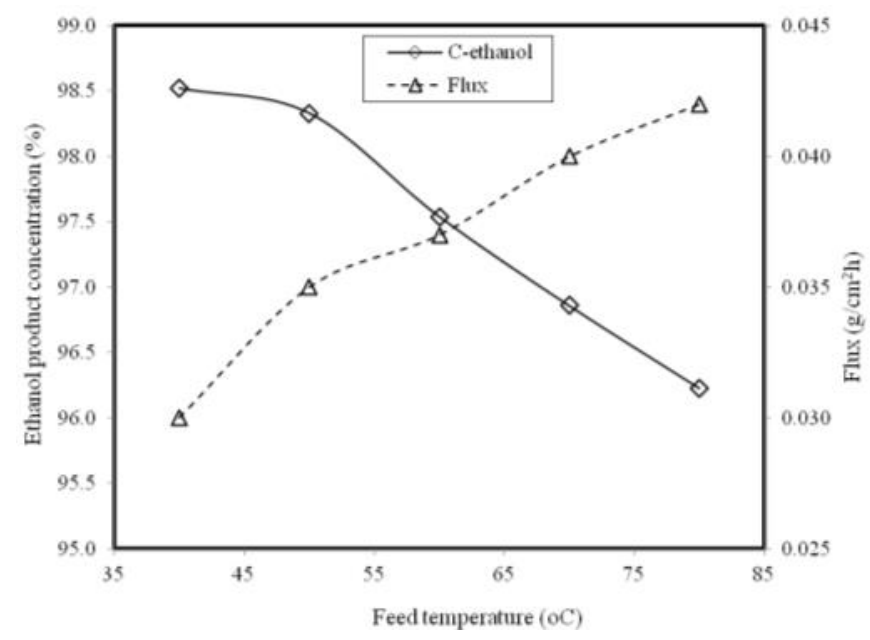

Figure 6. Effect of feed temperature on ethanol product concentration and flux. The feed ethanol concentration was of $95 \%$ and the pressure on permeate side was kept constant at $20 \mathrm{cmHg}$.

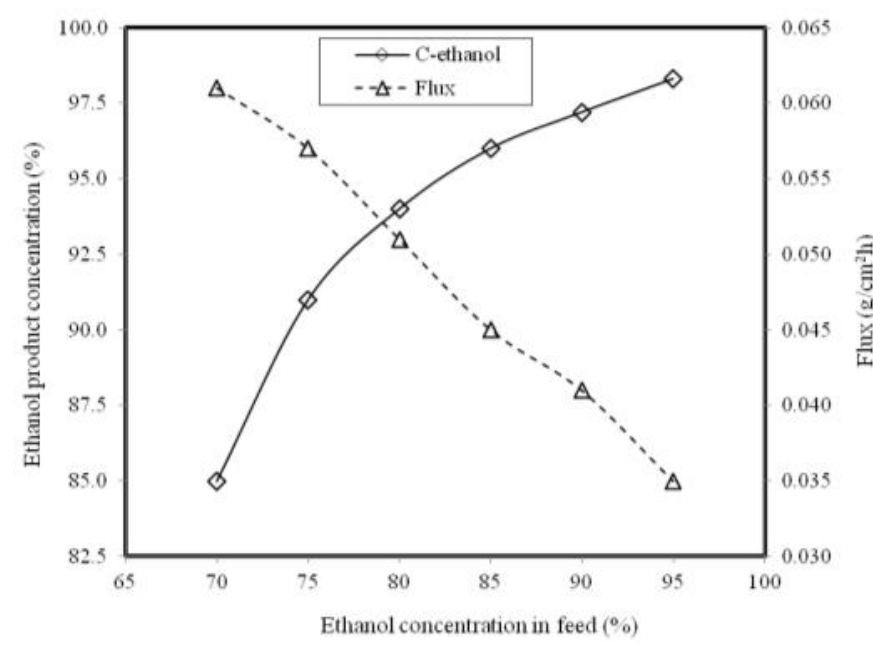

Figure 7. Effect of ethanol concentration in feed on ethanol product concentration and flux. The feed temperature was of $50{ }^{\circ} \mathrm{C}$ and the pressure on permeate side was kept constant at $20 \mathrm{cmHg}$. of ethanol could be increased to $~ 98.5 \%$. However, this concentration is lower than the standard required for fuel grade bioethanol. The reason for this condition is due to structure of the zeolite on porous support, which has not reached crystal structure.

\section{Conclusions}

Zeolite membrane has been made with support layer from a-alumina:kaolin $=50: 30$. That support has mechanical strength of $46.65 \mathrm{~N} / \mathrm{mm}^{2}$. Result of characterization using XRD indicates corundum and mullite phases were formed, which mullite phase was more dominant. Crystal size had an average size of 3.398 to $12.246 \mathrm{~nm}$ for corundum phase, while for mullite phase within the range 3.16 to $7.25 \mathrm{~nm}$. SEM image of zeolite membrane shows that zeolite crystals has been deposited on the support surface, even though they did not spread evenly on the support surface. It seems that the crystallization process has not been optimally occurred. Some cavities can still be observed.

The performance examination showed that the resulting zeolite membrane has followed process mechanism of pervaporation process. The concentration of ethanol could be increased to $~ 98.5 \%$ wt. but it was still lower than the standard required for fuel grade bioethanol.

\section{Acknowledgments}

The authors thank to Diponegoro University for the financial support of this research.

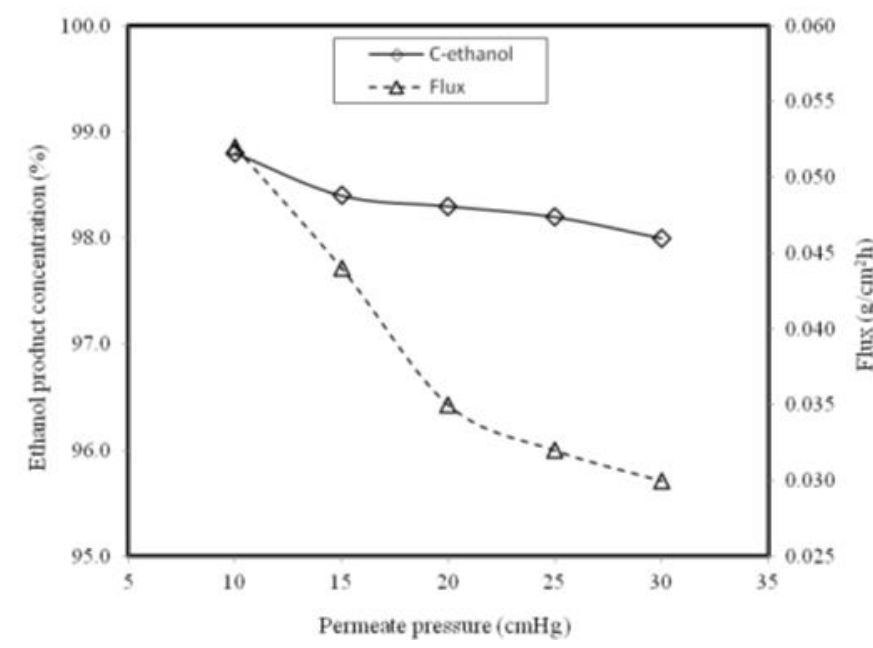

Figure 8. Effect of permeate pressure on ethanol product concentration and flux. The feed ethanol concentration was of $95 \%$ and the feed temperature was kept constant at $50{ }^{\circ} \mathrm{C}$. 


\section{References}

[1] Carmo, M.J., Gubulin, J.C. (2002). Ethanol-Water Separation in The PSA Process. Adsorption. 8: 235-248.

[2] Jeong, J.S. Jang, B.U. Kim, Y.R., Chung, B.W. (2009). Production of Dehydrated Fuel Ethanol by Pressure Swing Adsorption Process in The Pilot Plant. Korean J. Chem. Eng. 26(5): 1308-1312.

[3] Al-Amer, A.M. (2000). Investigating Polymeric Entrainers for Azeotropic Distillation of The Ethanol/Water and MTBE/Methanol Systems. Ind. Eng. Chem. Res. 39: 3901-3906.

[4] Chianese, A., Zinnamosca, F. (1990). Ethanol Dehydration by Azeotropic Distillation with A Mixed-Solvent Entrainer. Chem. Eng. J. 43: 5965.

[5] Hunek, J., Gal, S., Posel, E., Glavic, P. (2004). Separation of An Azeotropic Mixture by Reverse Extractive Distillation. AIChE J. 35: 1207-1210.

[6] Baker, R.W. (2000). Membrane Technology and Applications, McGraw-Hill, New York, USA
[7] Baelen, D.V., Bruggen, B.V., Dungen, K.V., Degreve, J., Vandecasteele, C. (2005). Prevaporation of Water-Alcohol Mixture and Acetic Acid-Water Mixture. Chem. Eng. Sci. 60: 1583-1590.

[8] Wee, S.L., Tye, C.T., Bhatia, S. (2008). Membrane Separation Process-Prevaporation Through Zeolite Membrane. Sep. Purif. Technol. 63: 500-516.

[9] Mohammadi, T., Kazemimoghadam, M. (2010). The Pilot-Scale Pervaporation Plant Using Tubular-Type Module with Nano Pore Zeolite Membrane. Desalination. 255: 196-200.

[10] Aguado, S., Gascón, J., Jansen, J.C., Kapteijn, F. (2009). Continuous Synthesis of NaA Zeolite Membranes. Micropor. Mesopor. Mater. 120: 170176.

[11] Reed, J.S. (1995). Principles of Ceramics Processing. John Wiley \& Sons, New York.

[12] Wee, S.L., Tye, C.T., Bhatia, S. (2011). Synthesis, Characterization and Pervaporation Properties of Microwave Synthesized Zeolite A Membrane. Desalination. 277: 383-389. 